\title{
Peritumoral Brain Edema
}

National Cancer Institute

\section{Source}

National Cancer Institute. Peritumoral Brain Edema. NCI Thesaurus. Code C121674.

An intracranial edema that develops around a tumor in the meninges or brain. 